\title{
Basal encephalocele and morning glory syndrome
}

\author{
JOSEPH CAPRIOLI AND ROBERT L. LESSER \\ From the Department of Ophthalmology and Visual Sciences, Yale University School of Medicine, \\ New Haven, Connecticut, USA
}

SUMMARY Basal encephaloceles are often associated with other midline anomalies such as hypertelorism, broad nasal root, cleft lip, and cleft palate. Optic disc anomalies such as pallor, dysplasia, optic pit, coloboma, and megalopapilla have been reported to occur in patients with basal encephalocele We report a case of a child with a sphenoethmoidal encephalocele and morning glory syndrome of the optic nerve. The presence of such optic nerve anomalies with facial midline anomalies should alert the clinician to the possible presence of a basal encephalocele.

Basal encephaloceles are classified in accordance with their location as trans-sphenoidal, spheno-orbital, sphenoethmoidal, transethmoidal or, sphenomaxillary. ${ }^{1}$ Although the transethmoidal is the most frequent, these are all rare anomalies, accounting for about $1.5 \%$ of all encephaloceles. ${ }^{2}$

Basal encephaloceles are often associated with other midline anomalies such as hypertelorism, broad nasal root, cleft lip, and cleft palate. ${ }^{13-5}$ Optic nerve anomalies such as disc pallor, pit of the optic nerve head, coloboma, optic nerve dysplasia, and megalopapilla have been reported in patients with basal encephalocele. ${ }^{13-8}$ The finding of such abnormalities of the optic nerve along with hypertelorism and cleft lip or palate should lead to the suspicion of the presence of basal encephalocele.

We report here a case of a child with a sphenoethmoidal encephalocele associated with morning glory syndrome of the optic nerve head and macular hypoplasia.

\section{Case report}

A 17-month-old white male was referred to the Neuro-Ophthalmology Service in November 1976 for investigation of 'papilloedema' of the left eye. He was born with a cleft lip and palate, was normal neurologically, and had normal milestones for growth and development. The child had chronic otitis media since the age of 2 months, for which he had been treated with oral antibiotics. At the age of 6 months he underwent successful repair of the cleft lip. At 16

Correspondence to Robert L. Lesser, MD. Department of Ophthalmology and Visual Sciences, Yale University School of Medicine, 333 Cedar Street, New Haven, Connecticut 06510. USA. months of age he was admitted for repair of the cleft palate and was found to have a soft pulsatile mass of the posterior pharynx extending through the palatal defect. Plain skull films and laminography of the base of the skull revealed a midline bony defect extending from the anterior wall of the sella turcica through the anterior sphenoid and ethmoid sinuses (Figs. 1, 2, 3, 4).

On 14 November 1976 the patient underwent bifrontal craniotomy with repair of the encephalocele by elevation of the herniated chiasmatic cistern and placement of a wire mesh dural flap.

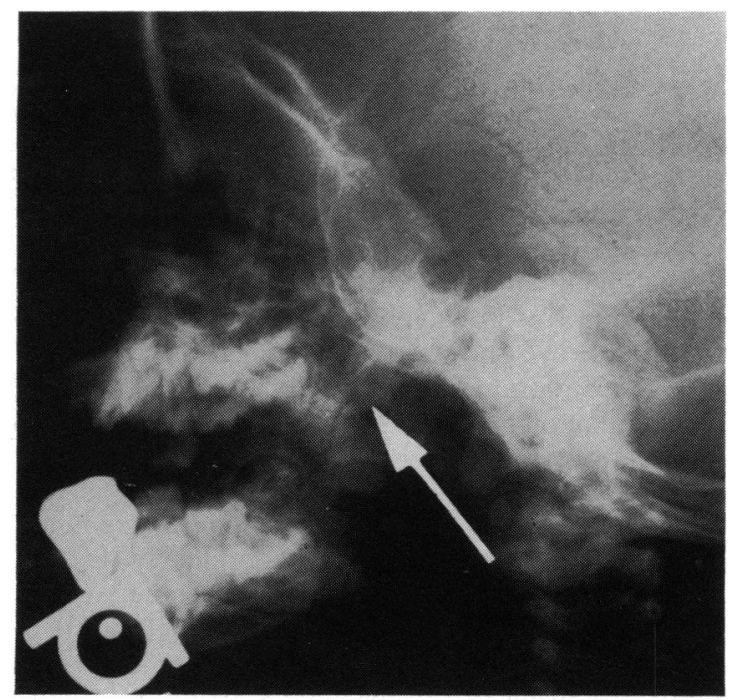

Fig. 1 Lateral view of skull showing encephalocele protruding into nasopharynx. 


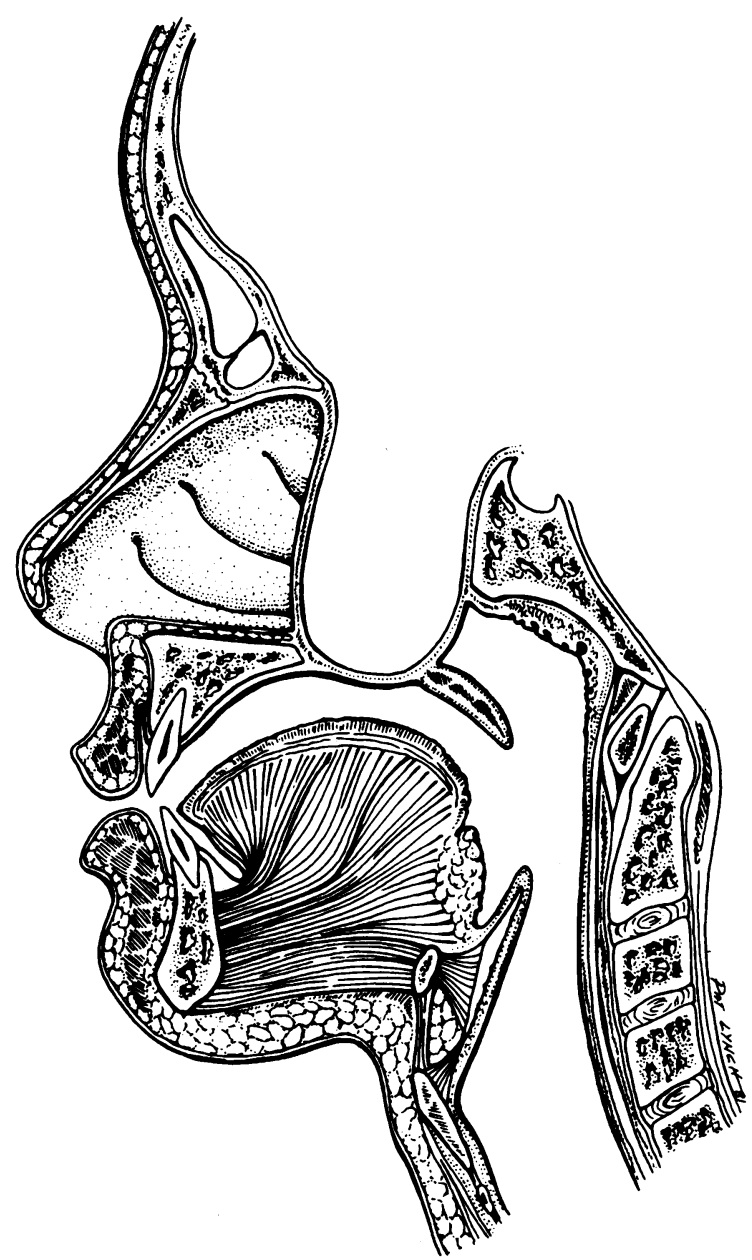

Fig. 2 Sagittal diagrammatic representation of sphenoethmoidal encephalocele with herniation of meninges and their contents into nasopharynx.

The patient fixed and followed light with each eye. A moderate degree of hypertelorism was present. Refraction under cyclopentolate revealed a hyperopia of 2.00 dioptres in each eye. The pupils were equal but the left eye showed a more sluggish reaction to light; a left afferent pupillary defect was present. The corneal diameters were $12 \mathrm{~mm}$ in each eye. Slit-lamp examination gave normal results. Applanation tonometry revealed pressures of $15 \mathrm{~mm} \mathrm{Hg}$ in the right eye and $13 \mathrm{~mm} \mathrm{Hg}$ in the left. Fundus examination of the right eye was entirely normal. In the left eye a large funnel-shaped optic disc was noted with a central glial tuft and a raised circumpapillary ridge which was lightly pigmented. The vessels radiated out from the margin of the disc in a spoke-like fashion (Fig. 5). No foveal reflex was present and no macular architecture could be identified.

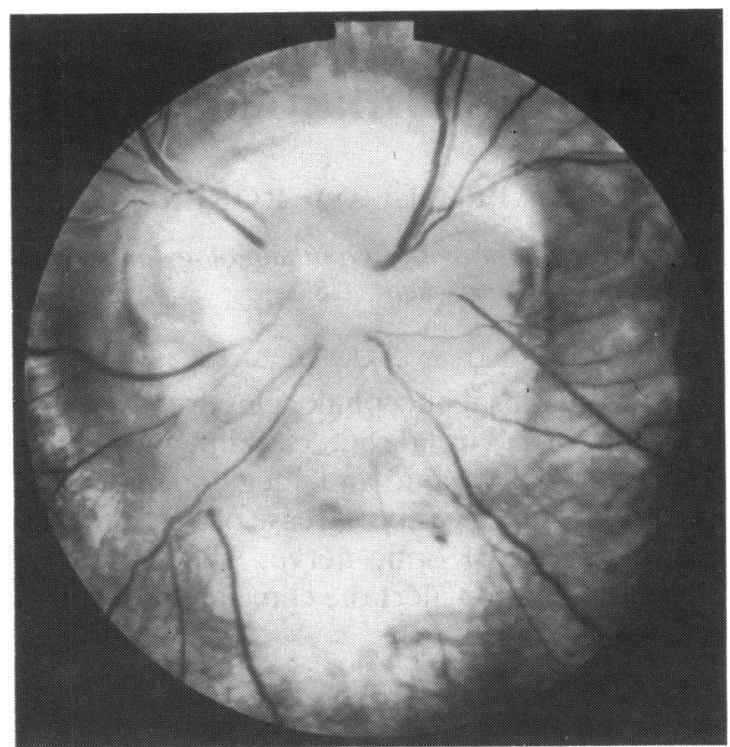

Fig. 3 Left optic nerve head of patient at age 17 months, with morning glory syndrome.

Recently examination showed a 5-year-old boy of normal intelligence. The visual acuity was $6 / 7 \cdot 5$ in the right eye and finger counting at 4 feet $(1.2 \mathrm{~m})$ in the left eye. Refraction under cyclopentolate revealed a hyperopia of 2.25 dioptres and 0.75 dioptre in the right and left eyes respectively. The motility was normal and the patient was orthophoric. The pupils measured $4 \mathrm{~mm}$ in diameter in the right eye and $5 \mathrm{~mm}$ in the left eye; light reaction was $4+$ on the right and

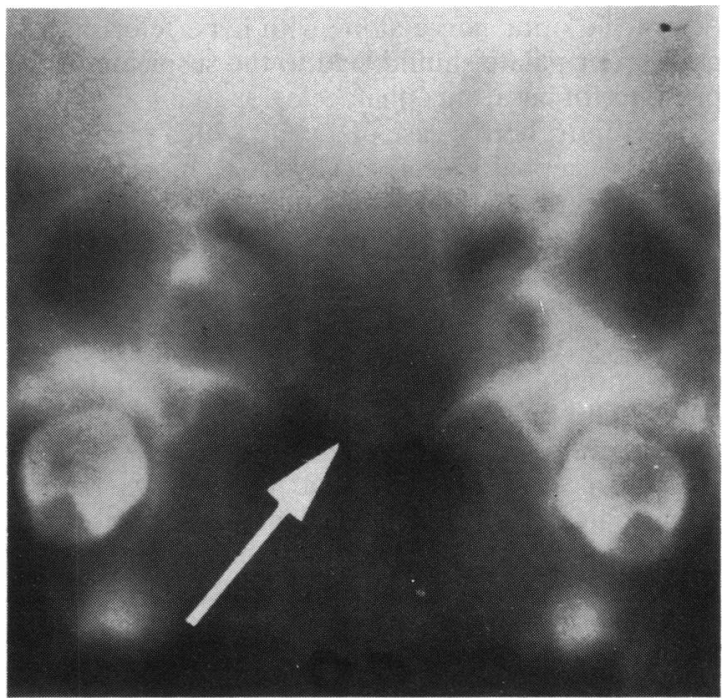

Fig. 4 Laminography in coronal plane revealing midline encephalocele. 


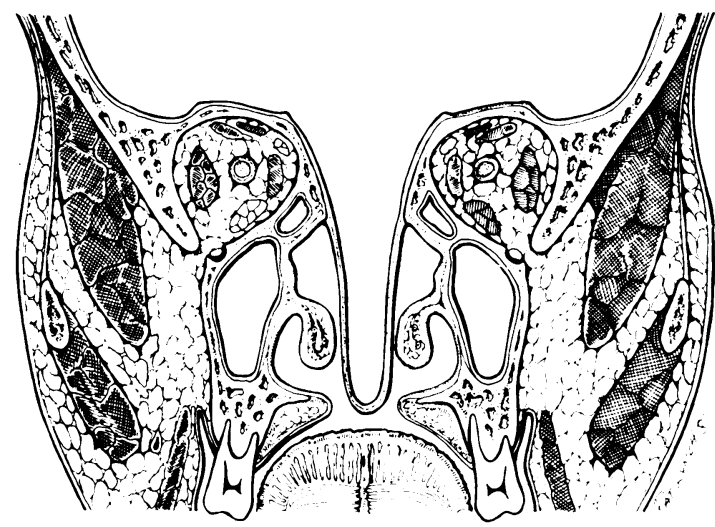

Fig. 5 Coronal diagrammatic representation of sphenoethmoidal encephalocele.

$1+$ on the left, and there was an afferent pupillary defect on the left. External examination showed moderate hypertelorism and a $2 \mathrm{~mm}$ ptosis on the left: there was $10 \mathrm{~mm}$ of levator function of both upper lids. Slit-lamp examination was unremarkable. The right fundus was normal. The ophthalmoscopic appearance of the left optic disc was unchanged from the previous examination. No well differentiated macula could be identified.

\section{Discussion}

Basal encephalocele is a rare midline bony defect of the base of the skull which may allow protrusion of the meninges and their contents. Herniated meninges in such cases may be found in the nasal cavity, nasopharynx, the sphenoid and ethmoid sinuses, the orbit. and the pterygopalatine fossa, the site depending on the location and size of the bony defect. ${ }^{1}$ Fig. 5 is a diagrammatic representation of a sphenoethmoidal encephalocele. These encephaloceles may present as a mass in the nasopharynx, masquerading as nasal polyps or enlarged adenoids, and may be associated with cleft palate. In cases in which the true identity of such masses was unknown, unfortunate surgical attempts at biopsy or repair of cleft palate have resulted in cerebrospinal fluid rhinorrhea, meningitis, and even death. ${ }^{13-5}$

Two physical findings which were uniformly present in a series of 8 cases reported by Pollock et al. ${ }^{\prime}$ were a broad nasal root and a congenital cystic mass located in the midline of the nasal or epipharyngeal space. Hypertelorism is also usually present but may be mild and inconspicuous. Other less constant associated findings include cleft lip, cleft palate, agenesis of the corpus callosum, and spina bifida. ${ }^{137}$

Optic nerve anomalies which have been associated with basal encephaloceles have been reviewed by Goldhammer and Smith. ${ }^{6}$ They include aplasia. hypoplasia, pit of the optic nerve head, dysplasia. megalopapilla, and coloboma. An additional optic disc anomaly called the morning glory syndrome had been described by several authors, but to our knowledge had never been reported in association with basal encephalocele. Pollock et al. ${ }^{1}$ reported a case of basal encephalocele and optic disc anomaly described as a coloboma which has some of the characteristics of the morning glory syndrome.

In 1970 Kindler reported 10 cases of the morning glory syndrome. ${ }^{9}$ In each case the nerve head was funnel shaped, contained a central white dot of glial tissue, and was 'surrounded by an elevated annulus of chorioretinal pigment disturbance'. The retinal vessels radiate out from the edge of the disc as multiple narrow branches. The visual acuity was severely diminished in all cases. Krause emphasised the typical features of morning glory syndrome as being an excavated optic disc and an elevated circumpapillary ring of chorioretinal pigmentary disturbances. ${ }^{10}$

The presence of midline facial anomalies such as broad nasal root. hypertelorism. cleft lip. and cleft palate in association with anomalies of the optic nerve should alert the physician to the possible presence of an otherwise unrecognised basal encephalocele.

\section{References}

1 Pollock JA. Newton TH. Hoyt WF. Transsphenoidal and transethmoidal encephaloceles. Radiology 1968; 90: 442-53.

2 Ingraham FD, Swan H. Spina bifida and cranium bididum. $N$ Engl J Med 1943; 228: 559-63.

3 Van Nouhuys JM, Bruyn GW. Nasopharyngeal transsphenoidal encephalocele, craterlike hole in the optic disc, and agenesis of the corpus callosum; pneumoencephalographic visualization of a case. Psychiatr Neurol Neurochir (Amst) 1964; 67: 243-258.

4 Blumenfeld R, Skolnik EM. Intranasal encephaloceles. Arch Otolaryngol 1965; 82: 527-31

5 Davis CH Jr, Alexander E Jr. Congenital nasofrontal encephalomeningoceles and teratomas; review of seven cases. $J$ Neurosurg 1959; 16: 365-77.

6 Goldhammer Y, Smith JL. Optic nerve anomalies in basal encephalocele. Arch Ophthalmol 1975; 93: 115-8.

7 Lewin ML. Schuster MM. Transpalatal correction of basilar meningocele with cleft palate. Arch Surg 1965; 90: 687-93.

8 Walsh FB. Hoyt WF. Clinical Neuro-Ophthalmology. Baltimore: Williams and Wilkins, 1969: 673.

9 Kindler P. Morning glory syndrome: unusual congenital optic disc anomaly. Am J Ophthalmol 1970); 69: 376-84

10 Krause U. Three cases of the morning glory syndrome. Acta Ophthalmol (Kbh) 1972; 50: 188-98. 